\title{
Application of Discrete Element Method in Impact Problems*
}

\author{
Kaishin LIU**, Lingtian GAO $^{* *}$ and Shinji TANIMURA***
}

\begin{abstract}
In this paper, a new numerical algorithm based on the discrete element method is presented for analyzing the dynamic problems under impact loading. Based on the basic principle of continuum mechanics, a connective model for orthotropic media is derived using disk elements. It is also extended to a bilinear hardening elastic-plastic model for calculating the plastic deformation in metals. Moreover, Mohr-Coulomb type failure criterion is used to judge the failure of concrete, and a contact discrete model is added in the algorithm. So the algorithm can calculate not only the impact problems of continuum and non-continuum, but also the transient process from continuum to non-continuum. The wave propagation in orthotropic planes under impact loading is numerically simulated. Through comparing the results with those computed by other numerical methods and examining the stability of the numerical solution, the accuracy and efficiency of the algorithm are discussed. In addition, the transient respondences of a steel warhead penetrating a concrete disc harrow is simulated, and three kinds of basic damage forms of concrete disc harrow under different penetration velocities of warhead are summarized.
\end{abstract}

Key Words: Computation Mechanics, Numerical Analysis, Discrete Element Method, Impact, Stress Wave, Dynamic Failure

\section{Introduction}

Various mechanic phenomena can be observed in materials and structures under impact loading, such as stress wave propagation, large deformation, damage and failure. Numerical simulation is an effective measure for studying these problems. Among the numerical proceedings, the finite difference method, the finite element method (FEM), the boundary element method (BEM) and the method of characteristics ${ }^{(1)-(3)}$ are suitable for analyzing the dynamic behaviors of continuum. However, when damage or fracture appears, though these methods can accurately forecast the failure region of material, it is difficult for them to deal with such non-continuum, and additional special treatments, such as lattice remeshing and contact judgment, have to be added in the procedure of calculation. All these make the simulation of the entire failure process a time-consuming and space-consuming task.

* Received 16th June, 2003 (No. 03-4088)

** Department of Mechanics and Engineering Science, Peking University, Beijing, 100871 P.R. China.

E-mail: kliu@mech.pku.edu.cn

*** Department of Mechanical Systems Engineering, Aichi University of Technology, Gamagori-city, Aichi 4430047, Japan. E-mail: tanimura@aut.ac.jp
The DEM (Discrete Element Method or Distinct Element Method), which was first proposed by Cundall(4), is proved to be a successful tool for modeling noncontinuum, such as an assemblage of blocks or granular materials, and it has been widely used in geotechnical engineering and powder technology ${ }^{(5)-(7)}$. Recently, some researchers tried to use this method to simulate the failure and damage processes of brittle materials ${ }^{(8)-(10)}$, but the accuracy of these methods in the calculation of the dynamic responses of continuum is not validated. In fact, the calculation accuracy of the DEM for the continuum problems is still doubtful. Therefore, for the numerical simulation of dynamic process from continuum to non-continuum, some combined methods ${ }^{(11)-(13)}$, such as the DEM combined with FEM or BEM, are presented. In these methods, continuum problems are calculated by FEM or BEM, and when non-continuum appears, the calculation model can be shifted to the DEM automatically. Thus, these methods can exert the merits of both the DEM and FEM or BEM. However, it is difficult to ascertain the boundary and the shift criterion between the elements of DEM and the elements of FEM or BEM in these algorithms. It manifests that the exploitation of the efficient DEM model for continuum has important meaning for extending the application area of the DEM. 
In this paper, a connective discrete model based on the DEM for orthotropic media is proposed. By extending this model to a bilinear hardening elastic-plastic model, and adding Mohr-Coulomb type failure criterion and a contact discrete model for non-continuum, a numerical analysis code with a complete software package for prepost processing is presented. It can be used to calculate not only the impact problems of continuum and noncontinuum, but also the transient process from continuum to non-continuum. By using the connective model, the stress wave propagation due to a longitudinal pulse in a half-infinite orthotropic plate and a narrow finite orthotropic plate are simulated. Comparing the results with the corresponding results obtained by the method of characteristics and LS-DYNA ${ }^{(2)}$ code, the accuracy and efficiency of this algorithm are examined. In addition, transient responses of a steel warhead penetrating a concrete disc harrow are also simulated, which demonstrate the availability in the simulation of dynamic process from continuum to non-continuum under impact loading.

\section{Elastic Discrete Model for Continuum}

\subsection{Basic formulation}

In this section, an elastic discrete model for an orthotropic plate is considered. The plate is separated to assemblage of uniform rigid disk elements, which are linked by two kinds of springs (a normal spring and a tangential spring) as shown in Fig. 1. There also contain semi-disk elements on the neat boundary. For one of the closest arrangement, each element is surrounded by other six elements (see the seven elements in Fig. 1), which forms regular hexagon lattice. Taking element $i$ and any element $j$ that surrounds the element $i$ into consideration, we can set up two sets of right-hand Cartesian coordinates, one of which is for the global coordinates $(x, y)$ and the other for the local coordinates $(X, Y)$, respectively. If the material deforms from time $(t-\Delta t)$ to time $t$, the relative distance

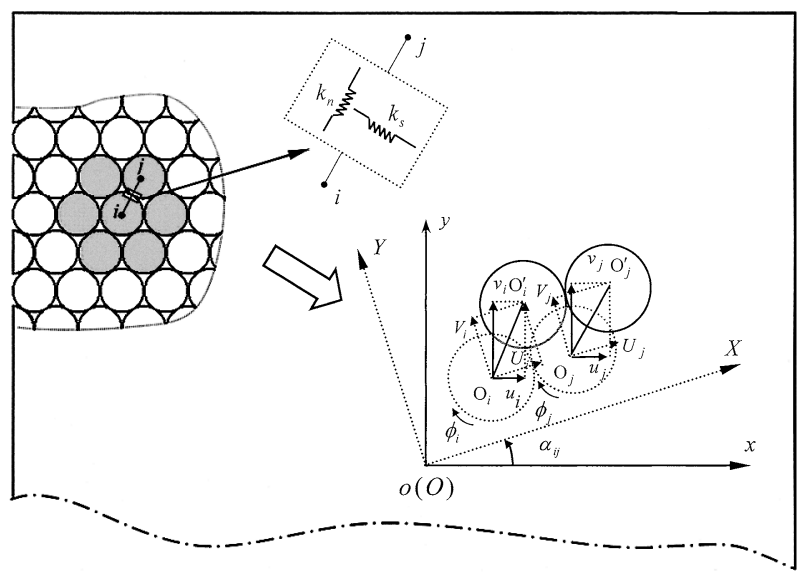

Fig. 1 Orthotropic plate and arrangement of discrete element of the elements will change. Then, the displacements are given as follows:

$$
\begin{aligned}
& \Delta u_{n}=-\left(\Delta u_{i}-\Delta u_{j}\right) \cos \left[\alpha_{i j}\right]_{t}-\left(\Delta v_{i}-\Delta v_{j}\right) \sin \left[\alpha_{i j}\right]_{t} \\
& \Delta u_{s}=\left(\Delta u_{i}-\Delta u_{j}\right) \sin \left[\alpha_{i j}\right]_{t}-\left(\Delta v_{i}-\Delta v_{j}\right) \cos \left[\alpha_{i j}\right]_{t} \\
& \quad+\left(r_{i} \Delta \phi_{i}+r_{j} \Delta \phi_{j}\right)
\end{aligned}
$$

where $\Delta u_{n}$ and $\Delta u_{s}$ are the displacement increments in normal and tangential direction respectively, $\left[\alpha_{i j}\right]_{t}$ the angle between the center line of the two elements and the coordinate axis $x$ at time $t, \Delta u_{i}, \Delta u_{j}, \Delta v_{i}, \Delta v_{j}, \Delta \phi_{i}$ and $\Delta \phi_{j}$ the displacement increments and the rotation angle increments between element $i$ and $j$ respectively in the global coordinates for a time increment $\Delta t, r_{i}$ the radius of element $i$. According to the Hooke's law, the interaction forces at the contact point along the normal direction and the tangential direction $\left[f_{n}\right]_{t}$ and $\left[f_{s}\right]_{t}$ are given by

$$
\left[f_{n}\right]_{t}=\left[f_{n}\right]_{t-\Delta t}+k_{n} \cdot \Delta u_{n}, \quad\left[f_{s}\right]_{t}=\left[f_{s}\right]_{t-\Delta t}+k_{s} \cdot \Delta u_{s}(2)
$$

where $k_{n}$ and $k_{s}$ are the spring constants between the element $i$ and $j$ along normal and tangential direction respectively, and taking the assumption of small deformation, the deformations of these two springs do not affect each other. The resultant forces and moments are expressed as

$$
\left\{\begin{array}{l}
{\left[F x_{i}\right]_{t}=\sum_{j=1}^{6}\left(\left[f_{n}^{j}\right]_{t} \cos \left[\alpha_{i j}^{j}\right]_{t}-\left[f_{s}^{j}\right]_{t} \sin \left[\alpha_{i j}^{j}\right]_{t}\right)} \\
{\left[F y_{i}\right]_{t}=\sum_{j=1}^{6}\left(\left[f_{n}^{j}\right]_{t} \sin \left[\alpha_{i j}^{j}\right]_{t}+\left[f_{s}^{j}\right]_{t} \cos \left[\alpha_{i j}^{j}\right]_{t}\right)} \\
{\left[M_{i}\right]_{t}=-r_{i} \sum_{j=1}^{6}\left[f_{s}\right]_{t}}
\end{array}\right.
$$

According to Newton's second law of motion, the equations of motion for the element $i$ are written by

$$
\begin{aligned}
& m_{i}\left[\ddot{x}_{i}(t)\right]_{t}=\left[F x_{i}\right]_{t}, \quad m_{i}\left[\ddot{y}_{i}(t)\right]_{t}=\left[F y_{i}\right]_{t}, \\
& I_{i}\left[\ddot{\phi}_{i}(t)\right]_{t}=\left[M_{i}\right]_{t}
\end{aligned}
$$

where $m_{i}$ denotes the mass of element $i, \ddot{x}_{i}(t)$ and $\ddot{y}_{i}(t)$ are the linear acceleration in the $x$ and $y$ directions respectively, and $\ddot{\phi}_{i}(t)$ the angular acceleration. The central difference is used for the integration of motion equations, so the velocities, the angular velocity, the displacements and the rotational angle are given by

$$
\left\{\begin{array}{l}
{\left[\dot{x}_{i}\right]_{t+\Delta t / 2}=\left[\dot{x}_{i}\right]_{t-\Delta t / 2}+\Delta t\left[\ddot{x}_{i}\right]_{t},} \\
{\left[x_{i}\right]_{t+\Delta t}=\left[x_{i}\right]_{t}+\Delta t\left[\dot{x}_{i}\right]_{t+\Delta t / 2},} \\
{\left[\dot{x}_{i}\right]_{t}=\frac{1}{2}\left(\left[\dot{x}_{i}\right]_{t-\Delta t / 2}+\left[\dot{x}_{i}\right]_{t+\Delta t / 2}\right)} \\
{\left[\dot{y}_{i}\right]_{t+\Delta t / 2}=\left[\dot{y}_{i}\right]_{t-\Delta t / 2}+\Delta t\left[\ddot{y}_{i}\right]_{t},} \\
{\left[y_{i}\right]_{t+\Delta t}=\left[y_{i}\right]_{t}+\Delta t\left[\dot{y}_{i}\right]_{t+\Delta t / 2},} \\
{\left[\dot{y}_{i}\right]_{t}=\frac{1}{2}\left(\left[\dot{y}_{i}\right]_{t-\Delta t / 2}+\left[\dot{y}_{i}\right]_{t+\Delta t / 2}\right)} \\
{\left[\dot{\phi}_{i}\right]_{t+\Delta t / 2}=\left[\dot{\phi}_{i}\right]_{t-\Delta t / 2}+\Delta t\left[\ddot{y}_{i}\right]_{t},} \\
{\left[\phi_{i}\right]_{t+\Delta t}=\left[\phi_{i}\right]_{t}+\Delta t\left[\dot{\phi}_{i}\right]_{t+\Delta t / 2},} \\
{\left[\dot{\phi}_{i}\right]_{t}=\frac{1}{2}\left(\left[\dot{\phi}_{i}\right]_{t-\Delta t / 2}+\left[\dot{\phi}_{i}\right]_{t+\Delta t / 2}\right)}
\end{array}\right.
$$




\subsection{Determination of spring constants}

In this section, the mechanical relationships between elastic coefficients for the orthotropic plate and the spring constants in the elastic discrete model are investigated. Taking assumption that elastic potential energy in continuum is totally stored in normal and tangential springs between element $i$ and its contiguous elements (shown in Fig. 1), the average strain energy around element $i$ can be given by

$$
e_{i}=r^{2} \sum_{j=1}^{6}\left[k_{n i j}\left(\partial u_{n i j} / \partial x_{n i j}\right)^{2}+k_{s i j}\left(\partial v_{s i j} / \partial y_{s i j}\right)^{2}\right]
$$

where $k_{n i j}$ and $k_{s i j}$ are the spring constants along normal and tangential directions between two elements respectively. $\partial u_{n i j} / \partial x_{n i j}$ and $\partial v_{s i j} / \partial y_{s i j}$ are the strains along normal and tangential directions, which can be expressed by

$$
\begin{aligned}
& \partial u_{n i j} / \partial x_{n i j}=l^{2} \varepsilon_{11}+m^{2} \varepsilon_{22}+2 \operatorname{lm} \varepsilon_{12}, \\
& \partial u_{s i j} / \partial y_{s i j}=\operatorname{lm}\left(\varepsilon_{22}-\varepsilon_{11}\right)+\left(l^{2}-m^{2}\right) \varepsilon_{12}+\beta
\end{aligned}
$$

where $l=\cos \left(\alpha_{i j}\right), m=\sin \left(\alpha_{i j}\right), \varepsilon_{12}=\varepsilon_{21}=\frac{1}{2}(\partial v / \partial x+$ $\partial u / \partial y), \varepsilon_{11}=\partial u / \partial x, \varepsilon_{22}=\partial v / \partial y, \beta=\frac{\phi_{i}+\phi_{j}}{2}, \phi_{i}$ and $\phi_{j}$ are the rigid rotation angles of element $i$ and element $j$. The strain energy density of the seven elements is given by

$$
e=e_{i} / \mathrm{Vol}
$$

where $\mathrm{Vol}$ is the equivalent volume over the hexagon, which is the area of circumscribed regular hexagon of disk elements. It is defined by

$$
\text { Vol }=2 \sqrt{3} r^{2} \delta
$$

where $\delta$ is the thickness of the plate. According to Green's formula, the stress components can be obtained by

$$
\sigma_{l m}=\partial e / \partial \varepsilon_{l m} \quad(l, m=1,2)
$$

Thus, the relationship between strain and stress expressed through spring coefficients can be obtained by

$$
\left\{\begin{array}{l}
\sigma_{11}=\frac{\sqrt{3}}{12}\left(8 \sqrt{3} k_{n 1}+k_{n 2}+3 k_{s 2}\right) \varepsilon_{11}+\frac{\sqrt{3}}{4}\left(k_{n 2}-k_{s 2}\right) \varepsilon_{22} \\
\sigma_{22}=\frac{\sqrt{3}}{4}\left(k_{n 2}-k_{s 2}\right) \varepsilon_{11}+\frac{\sqrt{3}}{4}\left(3 k_{n 2}+k_{s 2}\right) \varepsilon_{22} \\
\sigma_{12}=\frac{\sqrt{3}}{6}\left(3 k_{n 2}+2 k_{s 1}+k_{s 2}\right) \varepsilon_{12}
\end{array}\right.
$$

Comparing Eq. (11) with the constitutive equation of the orthotropic plane stress problem, the spring constants can be obtained as

$$
\begin{array}{ll}
k_{n 1}=\frac{\sqrt{3} \delta}{6}\left(3 c_{11}+2 c_{12}-c_{22}\right), & k_{n 2}=\frac{\sqrt{3} \delta}{3}\left(c_{12}+c_{22}\right) \\
k_{s 1}=-\frac{2 \sqrt{3} \delta}{3}\left(c_{22}-3 c_{66}\right), & k_{s 2}=\frac{\sqrt{3} \delta}{3}\left(c_{22}-3 c_{12}\right)
\end{array}
$$

where $c_{11}, c_{12}, c_{22}$ and $c_{66}$ are the elastic coefficients of the orthotropic media. As shown in Fig. 1, $k_{n 1}$ and $k_{s 1}$ are the spring constants along normal and tangential directions when the angle between the central line of two elements and $x$ coordinate axis is $0^{\circ}, k_{n 2}$ and $k_{s 2}$ the spring constants along normal and tangential directions when the angle is $60^{\circ}$.

For the isotropic plane stress problem, the elastic constants can be easily yielded as

$$
c_{11}=c_{22}=\frac{E}{1-\mu^{2}}, \quad c_{12}=\frac{\mu E}{1-\mu^{2}}, \quad c_{66}=\frac{E}{2(1+\mu)}=G
$$

where $E$ is Young's modulus, $\mu$ Possion's ratio, $G$ shear modulus. Then substituting Eq. (13) into Eq. (12), the following results can be yielded

$$
k_{n 1}=k_{n 2}=\frac{\sqrt{3}}{3} \cdot \frac{E \delta}{1-\mu}, \quad k_{s 1}=k_{s 2}=\frac{\sqrt{3}}{3} \cdot \frac{(1-3 \mu) E \delta}{1-\mu^{2}}
$$

These results are the same as the research results by Sawamoto, et al..$^{(9)}$ Similarly, the spring constants for the axisymmetric problem can be obtained as

$$
\begin{aligned}
& k_{n 1}=k_{n 2}=\frac{2 \sqrt{3} \pi}{3} \cdot \frac{b E}{(1+\mu)(1-\mu)}, \\
& k_{s 1}=k_{s 2}=\frac{2 \sqrt{3} \pi}{3} \cdot \frac{b(1-4 \mu) E}{(1+\mu)(1-2 \mu)}
\end{aligned}
$$

where $b$ is distance from element center to the central axis.

\section{Elastic-Plastic Discrete Model for Continuum}

When the plastic deformation appears in the material, a bilinear hardening elastic-plastic model for metals is used. The calculation of interaction forces between elements can be expanded as (see Fig. 2)

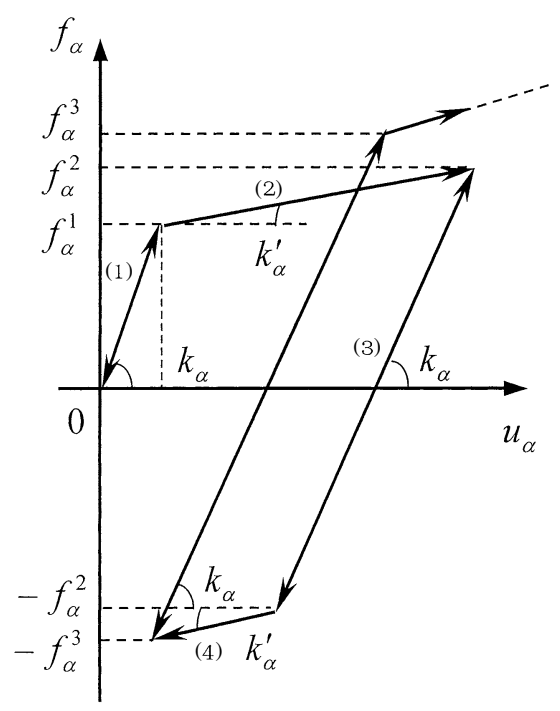

Fig. 2 Bilinear hardening elastic-plastic model 


$$
\left\{\begin{array}{lll}
{\left[f_{\alpha}\right]_{t}=\left[f_{\alpha}\right]_{t-\Delta t}+k_{\alpha} \cdot \Delta u_{\alpha}} & \text { for } & \left|\left[f_{\alpha}\right]_{t}\right| \leq f_{\alpha}^{l} \\
{\left[f_{\alpha}\right]_{t}=\left[f_{\alpha}\right]_{t-\Delta t}+k_{\alpha}^{\prime} \cdot \Delta u_{\alpha}} & \text { for } & f_{\alpha}^{l}<\left|\left[f_{\alpha}\right]_{t}\right|<f_{\alpha}^{l+1}
\end{array}\right.
$$

where $f_{\alpha}$ represents the interaction force of springs, $\Delta u_{\alpha}$ the displacement increment, $k_{\alpha}$ and $k_{\alpha}^{\prime}$ the spring coefficients in elastic and plastic condition respectively, in which the subscript $\alpha=n, s$ refers to normal and tangential direction, respectively. We take assumption that both normal springs and tangential springs obey the bilinear hardening elastic-plastic model. The superscript $l$ of $f_{\alpha}^{l}$ $(l=1,2,3, \ldots)$ represents the yield degree. Following the turn of loading path, if $\left|\left[f_{\alpha}\right]_{t}\right| \leq f_{\alpha}^{1}$ (see line (1) in Fig. 2), namely the value of spring force is less than the initial yield limit $f_{\alpha}^{1}$, the spring is in elastic condition, and loadon and load-off are elastic. If $f_{\alpha}^{1}<\left[f_{\alpha}\right]_{t}<f_{\alpha}^{2}$ (see line (2) in Fig. 2), where $f_{\alpha}^{2}$ is the second yield limit, namely it begins to unload from $f_{\alpha}^{2}$, the spring is in plastic condition, and load-on is plastic. However, if $\left|\left[f_{\alpha}\right]_{t}\right| \leq f_{\alpha}^{2}$ (see line (3) in Fig. 2), the spring begins to linearly harden, and loadon and load-off are elastic. If $-f_{\alpha}^{3}<\left[f_{\alpha}\right]_{t}<-f_{\alpha}^{2}$ (see line (4) in Fig. 2), namely the spring keeps to be loaded to the negative direction and exceeds the second yield limit $f_{\alpha}^{2}$, it gets into plastic condition again until it is loaded to the positive direction at $-f_{\alpha}^{3}$. Thus, the rest may be deduced by analogy, and the spring coefficients for the formula (16) can be obtained by the same technique shown in the section 2.2.

\section{Discrete Model for Non-Continuum and Failure Criterion}

For the numerical calculation of non-continuum (granular media), a contact model ${ }^{(14)}$ is used in our scheme. The interaction forces for the elastic discrete model shown in Eq. (2) can be changed as

$$
\begin{aligned}
& {\left[f_{n}\right]_{t}=\left[f_{n}\right]_{t-\Delta t}+\left(k_{n}-k_{n}^{*}\right) \Delta u_{n}} \\
& {\left[f_{s}\right]_{t}=\left[f_{s}\right]_{t-\Delta t}+\left(k_{s}-k_{s}^{*}\right) \Delta u_{s}}
\end{aligned}
$$

where $k_{n}^{*}=\beta k_{n}, k_{s}^{*}=\beta k_{s}, \beta$ is the coefficient of contact damping. In addition, the mass damping (also called global damping) is used for the calculation of the velocities, the angular velocity, the displacements and the rotation angle by integrating Eq. (4). For example, the velocities and angular velocity of disk elements can be taken as

$$
\left\{\begin{aligned}
{\left[\dot{x}_{i}\right]_{t+\Delta t / 2} } & =\frac{\left[\dot{x}_{i}\right]_{t-\Delta t / 2}(1-\lambda \cdot \Delta t / 2)+\left[\ddot{x}_{i}\right]_{t} \Delta t}{1+\lambda \cdot \Delta t / 2} \\
{\left[\dot{y}_{i}\right]_{t+\Delta t / 2} } & =\frac{\left[\dot{y}_{i}\right]_{t-\Delta t / 2}(1-\lambda \cdot \Delta t / 2)+\left[\ddot{y}_{i}\right]_{t} \Delta t}{1+\lambda \cdot \Delta t / 2} \\
{\left[\dot{\phi}_{i}\right]_{t+\Delta t / 2} } & =\frac{\left[\dot{\phi}_{i}\right]_{t-\Delta t / 2}(1-\lambda \cdot \Delta t / 2)+\left[\ddot{\phi}_{i}\right]_{t} \Delta t}{1+\lambda \cdot \Delta t / 2}
\end{aligned}\right.
$$

where $\lambda$ is the coefficient of mass damping. The other formulas are the same as those shown in chapter 2 .

When the failure appears, Mohr-Coulomb type failure criterion $^{(15)}$ is used for the simulation from continuum to non-continuum. In this criterion, springs between elements present two states (state I and state II). State I is the initial state of continuum. The interaction forces between a pair of elements are compression, tension and shear. When the tension force exceeds the tensile failure criterion, the state of springs changes to state II. In this state, tension forces can't work between elements from then on, and the connective condition between them changes from the connective model to the contact model.

The strain rate dependent parameters presented by Mekuro $^{(16)}$ are used in our model.

$$
F_{t}=f_{t d} \cdot 2 r, \quad F_{c}=f_{c d} \cdot 2 r, \quad C=c_{d} \cdot 2 r
$$

where $F_{t}, F_{c}$ and $C$ are the tensile strength, compressive strength and cohesive strength respectively, $c_{d}, f_{c d}, f_{t d}$ are the dynamic coefficients related with strain ratio $\dot{\varepsilon}_{t}$. For concrete it can be shown as ${ }^{(17)}$

$$
\left\{\begin{array}{l}
f_{t d}=\left[0.8743+0.02987 \log \dot{\varepsilon}_{t}+0.04379\left(\log \dot{\varepsilon}_{t}\right)^{2}\right] \cdot f_{t} \\
f_{c d}=\left[1.021-0.05076 \log \dot{\varepsilon}_{t}+0.02583\left(\log \dot{\varepsilon}_{c}\right)^{2}\right] \cdot f_{c} \\
c_{d}=c \cdot \sqrt{\left(f_{c d} / f_{c}\right) \cdot\left(f_{t d} / f_{t}\right)}
\end{array}\right.
$$

where $f_{t}, f_{c}$ and $c$ are the coefficients under static forces.

In the procedure of discontinuous media calculation, collision detection algorithm is one of the most timeconsuming approaches. In order to speed up the calculation of non-continuum, a fast incremental sort-and-update $\operatorname{algorithm}^{(18)}$ is used in our code.

\section{Numerical Results and Discussions}

\subsection{Stress wave propagation in orthotropic planes}

For validating the accuracy of our numerical algorithm, two examples of the wave propagation in orthotropic media are simulated.

In example one, the stress wave propagation process in an orthotropic half-space under a pressure pulse is calculated. The material parameters, the initial and boundary conditions are all the same as the orthotropic material B presented in Ref. (19). The elastic coefficients are $c_{11}=5.0961 \mathrm{GPa}, c_{12}=1.2256 \mathrm{GPa}, c_{22}=3.5359 \mathrm{GPa}$ and $c_{66}=1.2198 \mathrm{GPa}$, the mass density $\rho=1.244 \times 10^{3} \mathrm{~kg} / \mathrm{m}^{3}$; the initial and boundary conditions are given by (shown in Fig. 3)

$$
\begin{cases}\sigma_{x}=\sigma_{y}=\sigma_{x y}=0, \quad v_{x}=v_{y}=0 & \text { for } t=0 \\ \sigma_{y}=-p(x, t)=-p_{0} H(a-|x|) \exp \left(-\alpha_{c} t^{2}\right) \sin \left(\beta_{c} t\right), \\ \sigma_{x y}=0 & \text { for } y=0\end{cases}
$$

where $H(x)$ denotes Heaviside function, $\alpha_{c}=5.689 \times$ $10^{9} \mathrm{~s}^{-2}, \beta_{c}=2659 \mathrm{~s}^{-1}$, the loaded area is $a=20 \mathrm{~mm}$. Because the model described above is symmetrical, the half of this model is numerically calculated, where the element radius $r=0.5 \mathrm{~mm}$, the number of elements is 72394 , and time step $\Delta t=0.48 \mu \mathrm{s}$. Figure 4 shows the distributions 


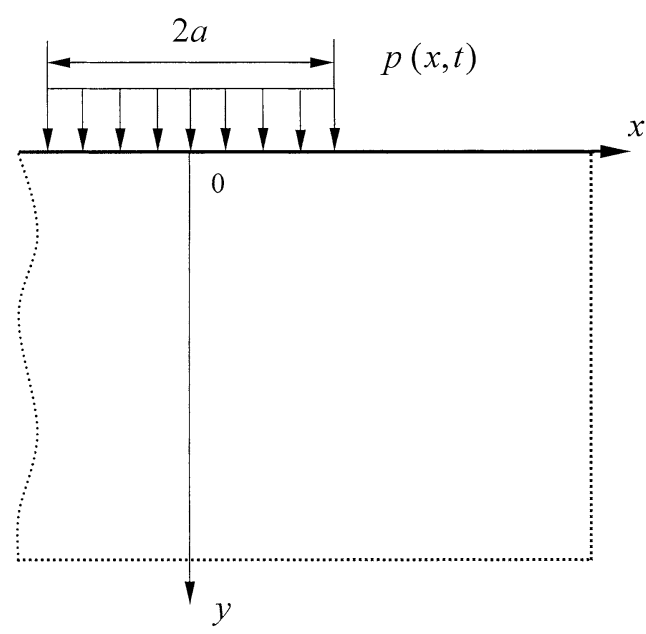

Fig. 3 Semi-infinite plate and coordinate system

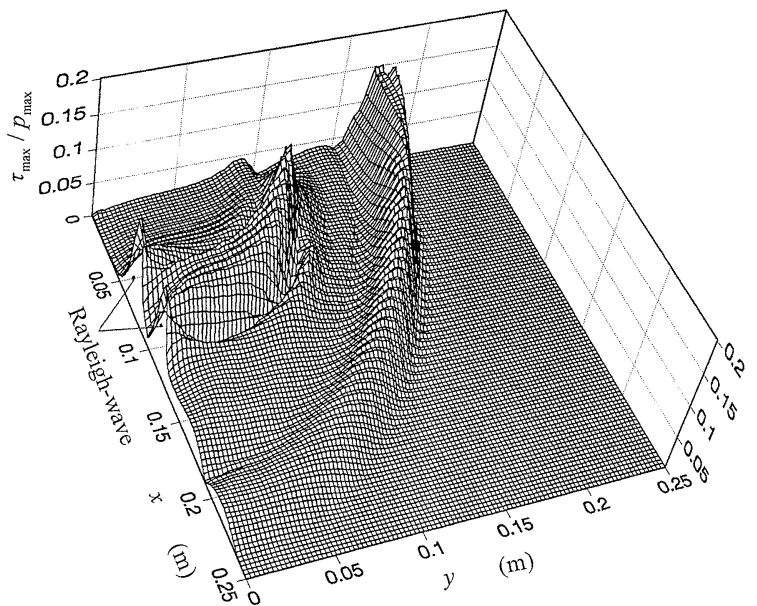

Fig. 4 Distributions of $\tau_{\max } / p_{\max }$ for the plate of composite at $t=104 \mu$ s by the DEM

of $\tau_{\max } / p_{\max }$ in the plate at time $t=104 \mu$ s calculated by the DEM, where $p_{\max }=\max [p(x, t)], \tau_{\max }$ the maximum shear stress. From this figure, we can clearly identify the quasi-longitudinal wave, the quasi-transverse wave, the von Schmidt wave and the two peaks of Rayleigh wave. Comparing Fig. 4 with the corresponding numerical result (see Fig. 5) obtained by the method of characteristics in Ref. (19), we can find that the two distributions of $\tau_{\max } / p_{\max }$ are almost the same. But the numerical results obtained by the present algorithm are not as smooth as the result calculated by the method of characteristics.

In example two, the stress distribution in a narrow finite orthotropic plate under impact loading is numerically calculated. As shown in Fig. 6, the initial and boundary conditions are given by

$$
\begin{cases}\sigma_{x}=\sigma_{x y}=0, \quad v_{x}=v_{y}=0 & \text { for } \quad t=0 \\ \sigma_{y}=-p(t), \quad \sigma_{x y}=0 & \text { for } \quad y=0\end{cases}
$$

where

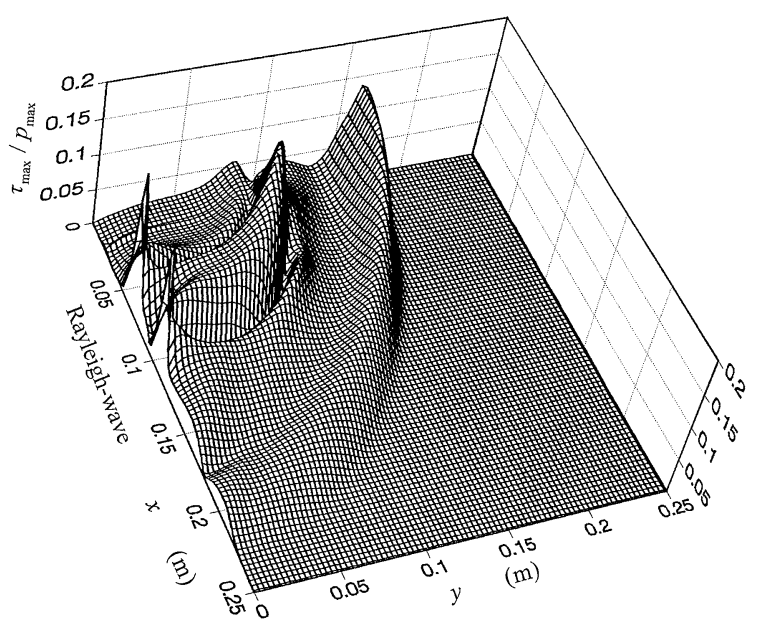

Fig. 5 Distributions of $\tau_{\max } / p_{\max }$ for the plate of composite at $t=104 \mu$ s by the method of characteristics

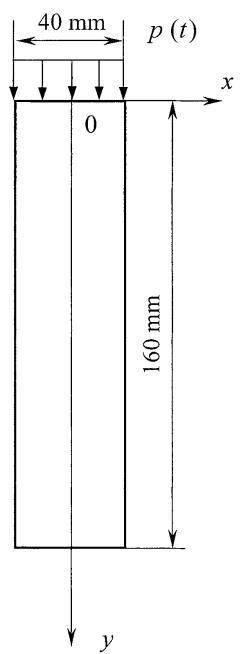

Fig. 6 Finite plate and coordinate system

$$
p(t)=\left\{\begin{array}{lll}
q_{0} t / t_{1} & \text { for } & 0 \leq t \leq t_{1} \\
q_{0} & \text { for } & t_{1} \leq t \leq t_{2}
\end{array}\right.
$$

where $q_{0}=10 \mathrm{MPa}, t_{1}=100 \mu \mathrm{s}, t_{2}=160 \mu \mathrm{s}$. The material parameter of the plate, element radius and time step are all the same as the example above. A half of this model is calculated, where the number of elements is 3792 . The results are compared with the corresponding results obtained by LS-DYNA. On the occasion using the LS-DYNA, SOLID164, size of elements $1 \mathrm{~mm} \times 1 \mathrm{~mm} \times 1 \mathrm{~mm}$ and time step $\Delta t$ of $0.48 \mu \mathrm{s}$ are chosen. Comparing the distributions of $\sigma_{y}$ at the time $t$ of $104 \mu$ s obtained by the two methods, as shown in Fig. 7, almost the same results are obtained.

\subsection{Stability of the numerical scheme}

In the practical numerical calculations, a principle to select the time step $\Delta t$, which is based on the formula for the free vibration of a simple pendulum, is approximated 


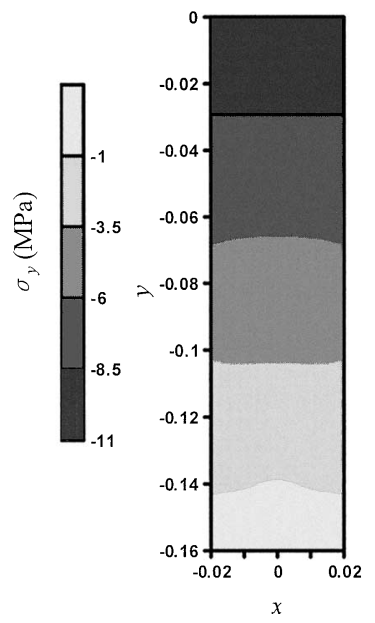

(a) By the DEM

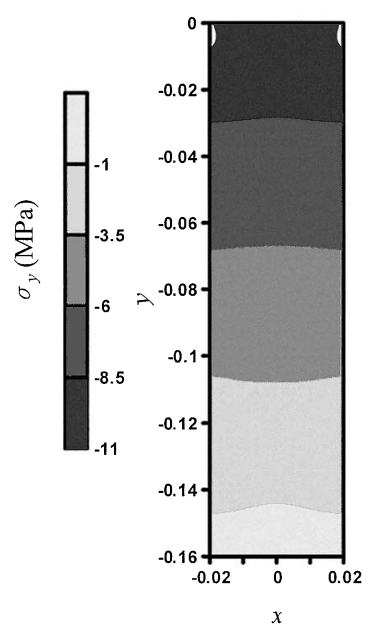

(b) By the LS-DYNA

Fig. 7 Comparison of the distribution of the $\sigma_{y}$ nephogram respectively solved by the DEM and the LS-DYNA

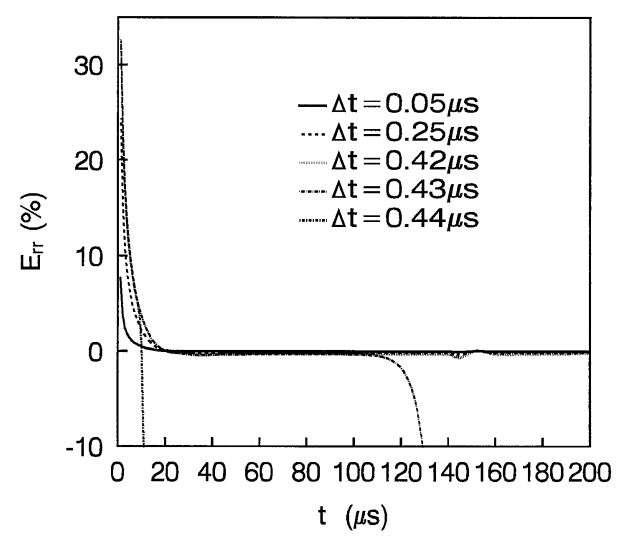

Fig. 8 Time variations of relative energy error involved in numerical solutions

as

$$
\Delta t \leq 2 / \omega_{\max }
$$

where $\omega_{\max }=\sqrt{k_{\max } / m}$ is the maximal circle frequency of the element-particle spring system, $m$ the mass of the element, $k_{\max }$ the maximum normal contact spring stiffness. For the material parameter of example 1 in the section 5.1, we obtained $\Delta t \leq 0.03 \mu \mathrm{s}$. As the effect of boundary condition and other factors are not taken into account in above analysis, formula (24) is just an approximate condition. However, it is still very useful for determining mesh ratio in numerical computation. In our numerical computation, the stability of the numerical procedure is evaluated by examining the relative energy error $E_{r r}$ in the system ${ }^{(20)}$, which is defined as

$$
E_{r r}=\left(E_{\mathrm{in}}-E_{t}\right) / E_{\mathrm{in}}
$$

where $E_{\text {in }}$ is the input energy and $E_{t}$ the total energy.

Figure 8 shows the time variations of the relative energy error for respective calculation conditions. Form

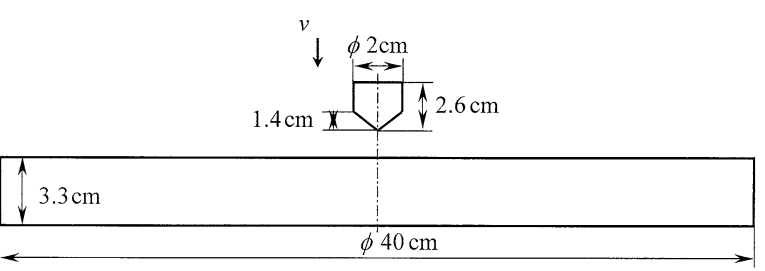

Fig. 9 A steel warhead penetrating a concrete disc harrow

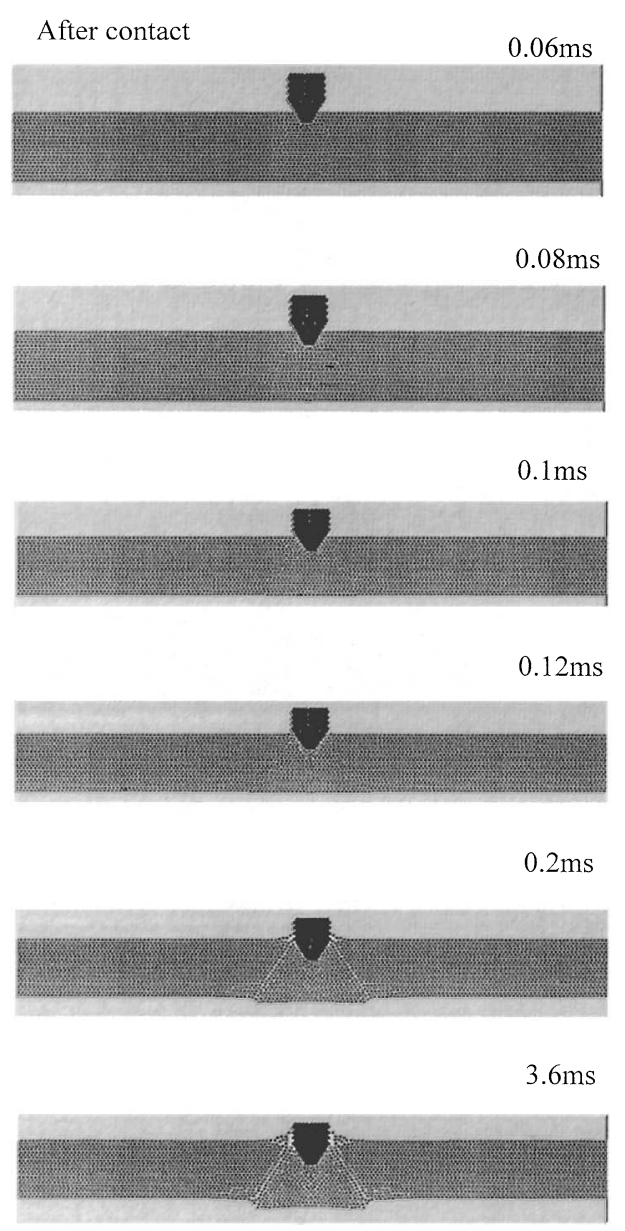

Fig. 10 The damage form under impact velocity $v=100 \mathrm{~m} / \mathrm{s}$

Fig. 8 , we can see that once $\Delta t$ is greater than $0.42 \mu \mathrm{s}$, the relative energy error quickly becomes excessively large. Therefore, formula (24) is just a commodious condition, but inefficient condition.

\subsection{A warhead penetrating a concrete disc harrow}

In this section, we simulate the whole process of a steel warhead penetrating a disc harrow at the speed of 100, 50 and $25 \mathrm{~m} / \mathrm{s}$. As shown in Fig. 9, the diameter of the warhead is $2 \mathrm{~cm}$, the whole length is $2.6 \mathrm{~cm}$ and the cone-shaped head is $1.4 \mathrm{~cm}$ in length. The thickness and the diameter of the disc harrow is $3.3 \mathrm{~cm}$ and $40 \mathrm{~cm}$ respectively. The parameters for concrete and steel are shown in Tables 1 and 2, respectively. The coefficient of 
Table 1 Material parameter of concrete

\begin{tabular}{ccccccccc}
\hline \multicolumn{7}{c}{ Concrete disc harrow } & Radius: $r=1 \mathrm{~mm}$ \\
\hline $\begin{array}{c}\text { Young's } \\
\text { modulus }\end{array}$ & $\begin{array}{c}\text { Poisson's } \\
\text { ratio }\end{array}$ & Density & $\begin{array}{c}\text { Cohesive } \\
\text { strength }\end{array}$ & $\begin{array}{c}\text { Tensile } \\
\text { strength }\end{array}$ & $\begin{array}{c}\text { Compression } \\
\text { strength }\end{array}$ & $\begin{array}{c}\text { Internal } \\
\text { friction angle }\end{array}$ & $\begin{array}{c}\text { Normal spring } \\
\text { stiffness }\end{array}$ & $\begin{array}{c}\text { Tangential spring } \\
\text { stiffness }\end{array}$ \\
\hline $\begin{array}{c}E \\
\mathrm{GPa}\end{array}$ & $\mu$ & $\begin{array}{c}\rho \\
\mathrm{kg} / \mathrm{m}^{3}\end{array}$ & $\begin{array}{c}C \\
\mathrm{MPa}\end{array}$ & $\begin{array}{c}F_{1} \\
\mathrm{MPa}\end{array}$ & $\begin{array}{c}F_{c} \\
\mathrm{MPa}\end{array}$ & $\varphi$ & $\begin{array}{c}k_{n} \\
\mathrm{~N} / \mathrm{m}\end{array}$ & $\begin{array}{c}k_{s} \\
\mathrm{~N} / \mathrm{m}\end{array}$ \\
\hline 23.3 & 0.2 & 2400 & 3.8416 & 2.3128 & 25.48 & $11.3^{0}$ & $1.868 \times 10^{10} \times \delta$ & $3.737 \times 10^{4} \times \delta$ \\
\hline
\end{tabular}

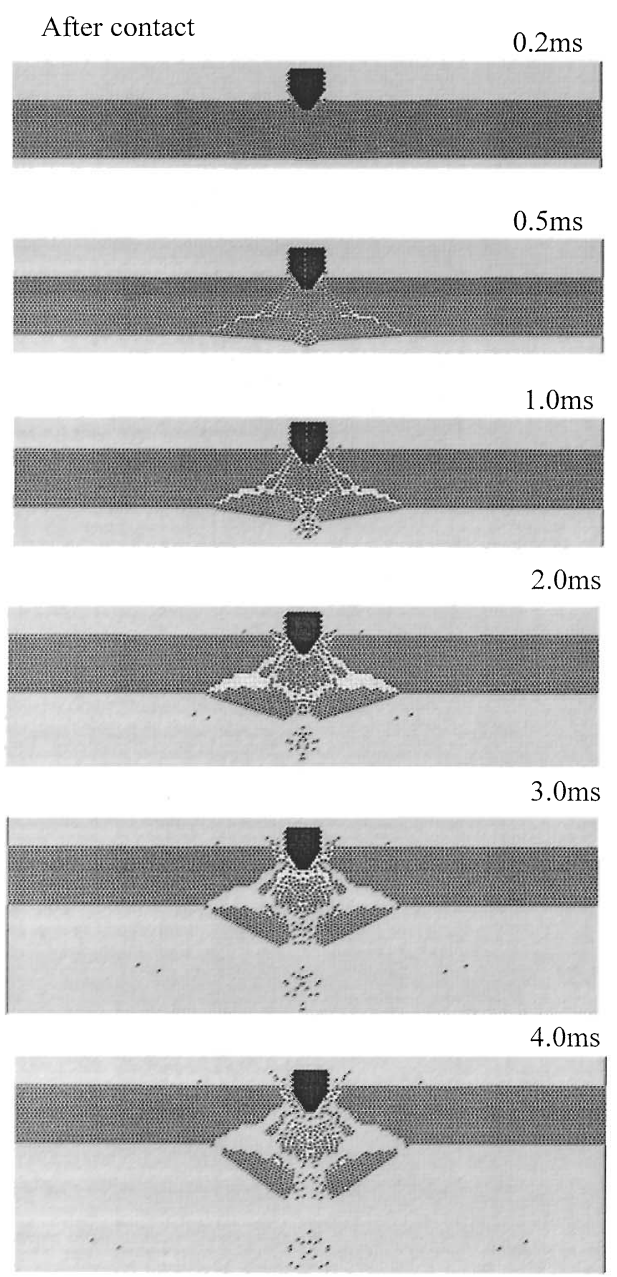

Fig. 11 The damage form under impact velocity $v=50 \mathrm{~m} / \mathrm{s}$

Table 2 Material parameter of the steel warhead

\begin{tabular}{|c|c|c|c|c|}
\hline & & Steel warhead & $\mathrm{s}: r=1 \mathrm{~mm}$ & \\
\hline Density & $\begin{array}{c}\text { Normal spring } \\
\text { stiffness (elasticity) }\end{array}$ & $\begin{array}{c}\text { Tangential spring } \\
\text { stiffness (elasticity) }\end{array}$ & $\begin{array}{c}\text { Normal spring } \\
\text { stiffness (plasticity) }\end{array}$ & $\begin{array}{c}\text { Tangential spring } \\
\text { stiffness (plasticity) }\end{array}$ \\
\hline $\begin{array}{c}\rho \\
\left(\mathrm{kg} / \mathrm{m}^{3}\right)\end{array}$ & $\begin{array}{c}k_{n} \\
(\mathrm{~N} / \mathrm{m})\end{array}$ & $\begin{array}{c}k_{s} \\
(\mathrm{~N} / \mathrm{m})\end{array}$ & $\begin{array}{c}k_{n}^{\prime} \\
(\mathrm{N} / \mathrm{m})\end{array}$ & $\begin{array}{c}k_{s}^{\prime} \\
(\mathrm{N} / \mathrm{m})\end{array}$ \\
\hline 7800 & $1.921 \times 10^{11} \times \delta$ & 0 & $1.549 \times 10^{9} \times \delta$ & 0 \\
\hline
\end{tabular}

mass damping is $\lambda=10^{-6} \mathrm{~s}^{-1}$, and the coefficient of contact damping is $\beta=0.5$. The time step $\Delta t=10^{-7} \mathrm{~s}$ is used in this simulation. The penetration process is shown in Figs. 10, 11 and 12. Comparing the damage forms at the velocities of $100 \mathrm{~m} / \mathrm{s}$ (see Fig. 10) and $50 \mathrm{~m} / \mathrm{s}$ (see Fig. 11) for the same penetration depth, we can find that: in a high
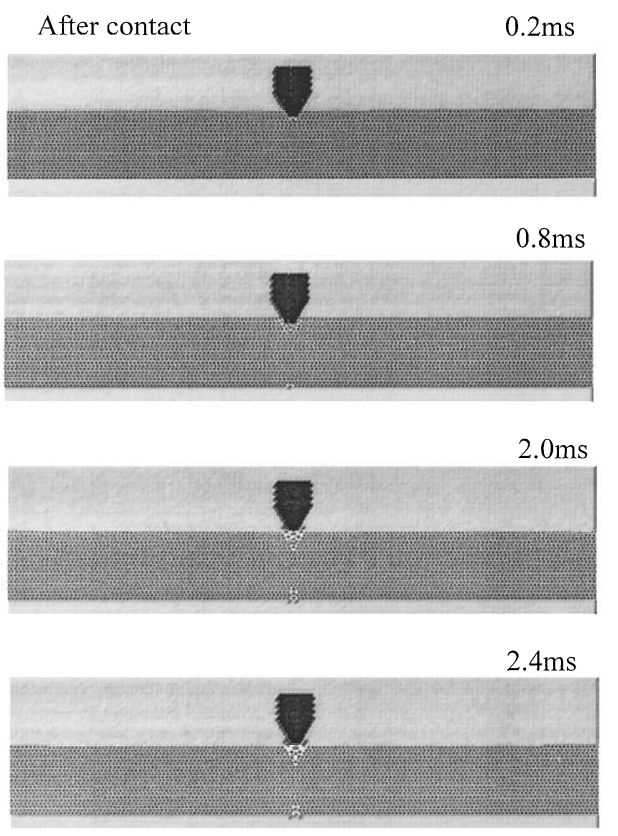

$3.2 \mathrm{~ms}$

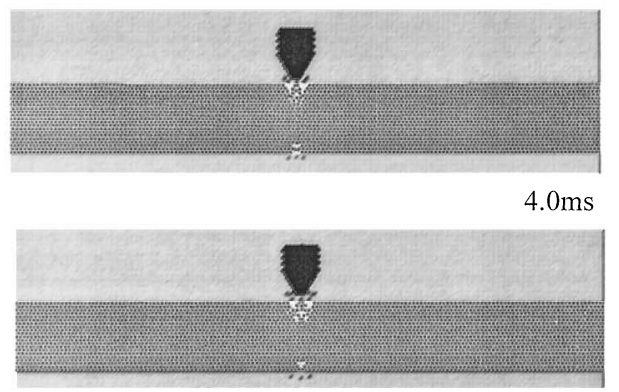

Fig. 12 The damage form under impact velocity $v=25 \mathrm{~m} / \mathrm{s}$

impact velocity, such as $100 \mathrm{~m} / \mathrm{s}$, cone-shaped cracks appear, and there is little pulverous local damage. In a lower impact velocity, such as $50 \mathrm{~m} / \mathrm{s}$, large crack is observed, and a lot of pulverous local damages appear. In a rather lower impact velocity, such as $25 \mathrm{~m} / \mathrm{s}$ (see Fig. 12), there is no large damage occurred inside the concrete harrow, but little fragment on the top and bottom of the concrete harrow, where the warhead taped out two small holes, and the warhead can be bounced to the opposite direction. These results show that impact velocities present great importance in determining damage form of penetration process.

Although the model of numerical simulation is rather simple, and the data are slightly rough, it also presents a 
basic damage form of concrete disc harrow as in experiments $^{(21)}$.

\section{Conclusions}

Summarizing the results above, we assert that the discrete element model proposed by us is efficient for the numerical analysis of impact problems in continuum. It also manifests that our algorithm is not only powerful in the dynamic analysis of continuum and non-continuum, but also available in the dynamic simulations of the transition process from continuum to non-continuum. By comparing the numerical results with the corresponding results computed by the method of characteristics, LS-DYNA and the results derived from experiments, the validity and accuracy of the algorithm were clearly demonstrated. However, our discrete model for continuum is limited by the assumption of small deformation. For expanding the application range of the algorithm, it is necessary to add a discrete model for large deformation problem, which will also be our future work.

\section{Acknowledgement}

The authors gratefully acknowledge the financial support of National Natural Science Foundation of China and Monbusho Scientific Research Program, Japan.

\section{References}

( 1 ) Clifton, R.J., A Difference Method for Plane Problems in Dynamic Elasticity, Q. Appl. Math., Vol.25 (1967), pp.97-116.

( 2 ) Hallquist, J.O., LS-DYNA Theoretical Manual, (1998), Livermore Software Technology Corporation.

( 3 ) Liu, K., Mimura, K. and Tanimura, S., ThreeDimensional Numerical Analysis of Dynamic ThermoElastic/Viscoplastic Problem by the Method of Characteristics, JSME Int. J., Ser. A, Vol.39, No.2 (1996), pp.216-222.

( 4 ) Cundall, P.A., A Computer Model for Simulating Progressive Large Scale Movement in Blocky Rock System, Symposium ISRM Proc. 2, (1971), pp.129-136.

( 5 ) Iwashita, K. and Oda, M., Micro-Deformation Mechanism of Shear Banding Process Based on Modified Distinct Element Method, Powder Technology, Vol.109 (2000), pp.192-205.

(6) Vu-Quoc, L., Zhang, X. and Walton, O.R., A 3-D Discrete-Element Method for Dry Granular Flows of Ellipsoidal Particles, Computer Methods in Applied Mechanics and Engineering, Vol.187 (2000), pp.483528.

( 7 ) Cleary, P.W., DEM Simulation of Industrial Particle
Flows: Case Studies of Dragline Excavators, Mixing in Tumblers and Centrifugal Mills, Powder Technology, Vol.109 (2000), pp.83-104.

( 8 ) Oda, J., Zhang, M. and Tohyama, K., Simulation of Impact Fracture Behavior of Laminated Glass Using Discrete Element Method, Trans. JSME, (in Japanese), Vol.63 (1997), pp.630-635.

( 9 ) Sawamoto, Y., Tsubota, H., Kasai, Y., Koshika, N. and Morikawa, H., Analytical Studies on Local Damage to Reinforced Concrete Structures under Impact Loading by Discrete Element Method, Nuclear Engineering and Design, Vol.179 (1998), pp.157-177.

(10) Camborde, F., Mariotti, C. and Donze, F.V., Numerical Study of Rock and Concrete Behaviour by Discrete Element Modelling, Computers and Geotechnics, Vol.27 (2000), pp.225-247.

(11) Mohammadi, S., Owen, D.R.J. and Peric, D., A Combined Finite/discrete Element Algorithm for Delamination Analysis of Composites, Finite Elements in Analysis and Design, Vol.28 (1998), pp.321-336.

(12) Ransing, R.S., Gethin, D.T., Khoei, A.R., Mosbah, P. and Lewis, R.W., Powder Compaction Modelling via the Discrete and Finite Element Method, Materials and Design, Vol.21 (2000), pp.263-269.

(13) Lorig, L.J., Brady, B.H.G. and Cundall, P.A., Hybrid Distinct Element-Boundary Element Analysis of Jointed Rock, Int. J. Rock Mech. Min. Sci. Geomech. Abstr., Vol.23 (1986), pp.303-312.

(14) Cundal, P.A. and Strack, O.D.L., A Discrete Numerical Model for Granular Assemblies, Geotechnique, Vol.29 (1979), pp.47-65.

(15) Mohr, O., Die Scherfestigkeit des Betons, (1991), pp.247-250, Armierter Beton.

(16) Mekuro, K. and Hakano, T., Concrete Fracture Analysis Using Granular Simulation, ERI Newsletter, (in Japanese), Vol.63 (1988), pp.409-468.

(17) Yamaguchi, H. and Fujimoto, K., Strain Rate Effect on Dynamic Response of Reinforced Concrete Slabs under Impact Loading, Trans. Arch. Inst. Jpn., (in Japanese), Vol.406 (1989), pp.25-36.

(18) Alexander, S., Fast Algorithms for the Simulation of Polygonal Particles, Granular Matter, Vol.2 (1999), pp.35-43.

(19) Liu, K. and Li, X., Numerical Simulation of Stress Wave Propagation in An Orthotropic Plate, Proceedings of The 2nd International Symposium On Impact Engineering, (1996), pp.19-24.

(20) Liu, K., Li, X. and Tanimura, S., Numerical Transient Wave Propagation in Layered Orthotropic Plates, JSME Int. J., Ser. A, Vol.42, No.3 (1999), pp.328-333.

(21) Rinehart, J.S. and Pearson, J., Behavior of Metals under Impulsive Loads, (1965), Dover Publication, Inc., New York. 